doi:10.22306/atec.v5i4.58

Received: 26 June 2019

Accepted: 08 Nov. 2019

\title{
OPERATION OF THE AUTOMATIC HEAT SOURCE ON PELLETS WITH VARIOUS BURNER TYPES
}

\author{
Michal Holubčík \\ Department of Power Engineering, University of Žilina, Univerzitná 1, 01026 Žilina, Slovak Republic, EU, \\ michal.holubcik@fstroj.uniza.sk (corresponding author) \\ Nikola Kantová \\ Department of Power Engineering, University of Žilina, Univerzitná 1, 01026 Žilina, Slovak Republic, EU, \\ nikola.kantova@fstroj.uniza.sk \\ Juraj Trnka \\ Department of Power Engineering, University of Žilina, Univerzitná 1, 01026 Žilina, Slovak Republic, EU, \\ juraj.trnka@fstroj.uniza.sk

\section{Jozef Jandačka} \\ Department of Power Engineering, University of Žilina, Univerzitná 1, 01026 Žilina, Slovak Republic, EU, \\ jozef.jandacka@fstroj.uniza.sk
}

Keywords: heat source, wood pellets, burner, biomass, boiler

Abstract: One of the most important issues in choosing a heating system is the question: What kind of fuel can be burned in given heating system. Modern automatic solid fuel boilers are often specialized only on a narrow range of suitable pellet materials. Pellets from cheaper sources are also beginning to appear on the market. However, many burners are unable to burn these new types of pellets without significant burning problems. The article deals with the influence of the proper construction of the burner on the smoothness of the combustion process and the smooth operation of the combustion equipment. The results of the experiments document the continuity of the combustion plant in the combustion of less quality pellets containing bark using more modern combustion technologies. In fact, less quality pellets cause the formation of ash sinters which cause the continuous combustion process to be interrupted, resulting in fluctuations in equipment performance and the onset of thermal discomfort. The results showed no problem with burning even when making sinters, but also showed a fluctuation in performance and the need for manual control, especially when heating or clogging the supply pipe. They also showed significant damage to pellets in the worm feeder section. These problems, therefore, ultimately require further research to ensure complete, seamless operation.

\section{Introduction}

\subsection{Solid fuels}

Automatic small heat sources for solid fuels most frequently use wood pellets as fuel. Pellets are small granulated cylinders of circular cross-section with a diameter of 2.5 to $8 \mathrm{~mm}$ with a length of up to $5 \mathrm{~cm}[1,2]$. Their unquestionable advantage is their normalized size, which allows us to continuously run the combustion and control the output of the combustion equipment as needed. In addition, we can use different types of materials to produce new types of fuel. However, this trend also brings with it some problems. The use of less quality biomass for combustion, changes the chemical composition of the fuel and, in particular, the ash content of the substances. These substances in plant fitness have been shown to have an effect on reducing the melting point of ash. The problem of plant ash is free oxides (and chlorides) which significantly reduce the value of the melting point of ash. Silicon dioxide plays an essential role in vitreous oxide and calcium oxide together with potassium oxide subsequently reduces the viscosity of the resulting melt $[3,4]$. The first is that they form meteor-like crystals that, due to their higher weight, remain in the burner and clog it and prevent new fuel from entering the burning process. They also settle on the burner walls and cause a reduction in the combustion space cross section [5]. The burner burners are particularly susceptible. The article deals with the appropriate design of the burner with respect to the mentioned problem.

\subsection{Influence of flame direction}

One of the most striking effects of combustion is the flame direction. In practice, it is possible to burn solid fuels in only two ways, either horizontally or vertically, or alternatively by combining these two methods. From our point of view, one of the most important factors in combustion is gravity, which acts on the unburned pellets as well as on the burnt residue of the ash. The ash itself will not become such a problem because small ash particles with their weight are easily blown out of the torch body $[6,7]$. The problem arises when sintering because the ash gains weight and the larger the sinter is, the greater the gravitational force acting on it. For this reason, vertical retort burners are unsuitable for incineration of lower quality biomass because the resulting sinters must go out directly against the gravitational force $[8,9]$. In tubular horizontal burners, the situation is much better as the 
sinters no longer have to overcome the gravitational but only frictional force on the tube wall and are mostly blown out of the burning process without problems. NO disadvantage of this system is that even unburned pieces of pellets can easily fall out of the burning process [10,11]. Some compromise is to tilt the burner upwards, at an angle at which the pellets would remain in the tube and burn smoothly. Otherwise, with extremely high sintering, the burner can be tilted down in the direction of gravity to prevent burner clogging. In our experiment, we compared the results of both systems as shown in figure 1 .

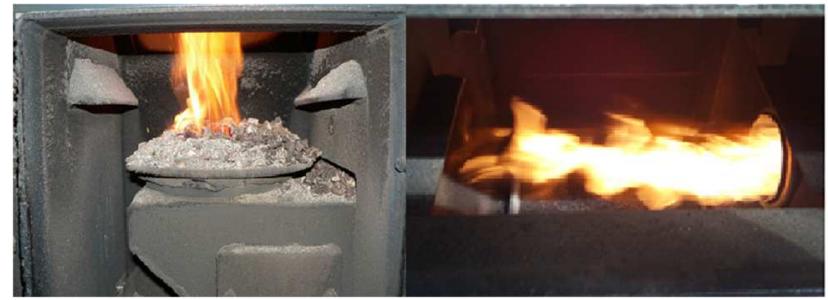

Figure 1 Flame direction - retort burner on the left, tube rotary burner on the right

\section{Materials and methods}

\subsection{Used fuel samples}

Spruce wood with different bark content was used as fuel (figure 2):

- sample 1 (V1) - 100\% bark-free spruce wood pellets,

- $\quad$ sample 2 (V2) - 95\% spruce wood pellets with bark content $5 \%$,

- $\quad$ sample 3 (V3) - 90\% spruce wood pellets with $10 \%$ bark,

- $\quad$ sample 4 (V4) - 80\% spruce wood pellets with a bark content of $20 \%$.

Prior to measurement, the moisture content of the individual samples was determined on a RADWAG 50 SX drying scale and calorific value using a LECO AC 500 calorimeter.
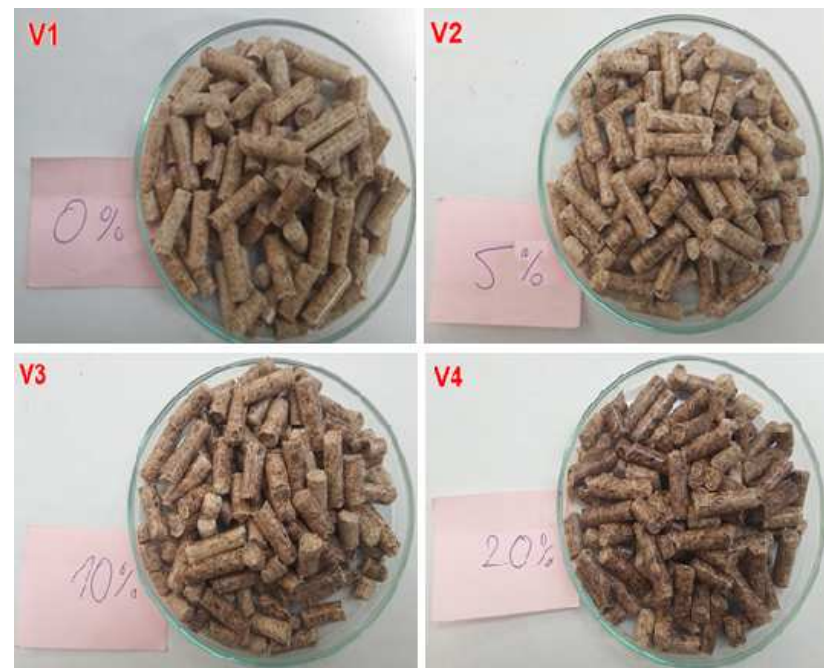

V4

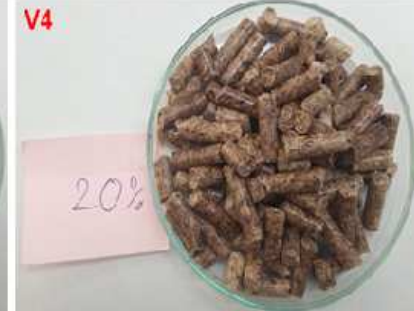

Figure 2 Wood pellets samples

\subsection{Methods of experiments}

The combustion took place in commercial small heat source USPOR 18 AUTOMAT with a rated heat output of $18 \mathrm{~kW}$ which was tested on an experimental device designed for the measuring of heat output and emission production. The connection of an automatic heat source to the experimental device can be seen in figure 3 . The device is built from an experimental boiler, a heat consumption device (i.e. device for regulation of heat produced by the boiler), a gaseous emission analyser, a particulate matter analyser, measuring apparatus to which all measuring instruments are connected and a computer for the processing of measured data. Various parameters are recorded every $20 \mathrm{~s}$. During the measurements constant chimney draft $12 \pm 2 \mathrm{~Pa}$ via a flue fan is ensured. Its speed is controlled by a frequency regulator.

Experimental measurements to determine the effect of the burner design on the combustion process were performed on a local heat source with a maximum power of $18 \mathrm{KW}$, where two types of burners were mounted. First, measurements were made with the original retort burner compatible with the source. Second measurements were made after replacing the retort burner with a newer type of rotary burner for which the combustion equipment had to be adapted. All pellet samples with various bark content were burned at the same operating settings of the boiler fuel feeding time of a spiral conveyor is $18 \mathrm{~s}$, idle time of the conveyor is $25 \mathrm{~s}$, the combustion air is set to constant air access. This operation mode correspond with the loading process in other works [11,12]. The boiler was operated on settings for nominal heat output during wood pellets with very good quality burning.

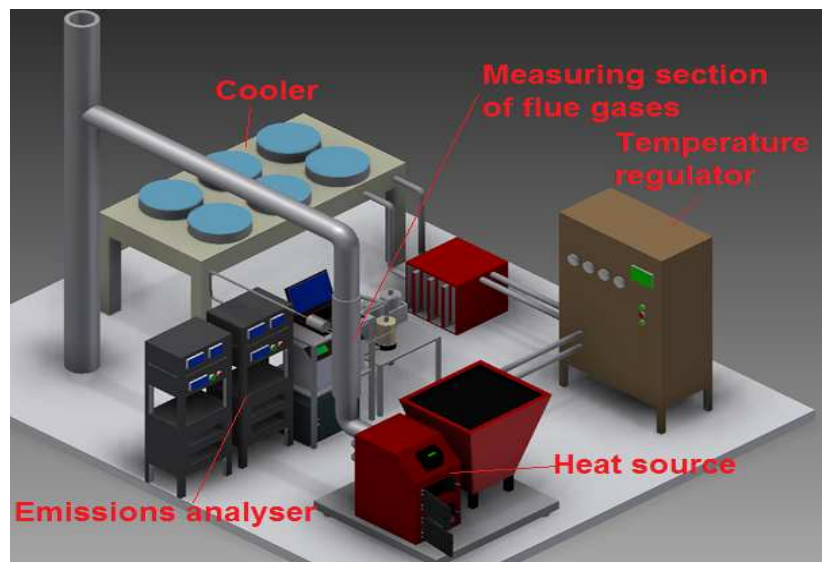

Figure 3 Experimental device for heat source testing

The thermal power of an experimental boiler was measured by calorimetric method where the flow of the heat transfer medium (water) was measured by a magnetic flow meter YOKOGAWA ADMAG AXF with an accuracy of $\pm 0.35 \%$. The temperature difference of the heat transfer medium (water) was measured by two paired resistance thermometers PT100 with a measurement accuracy $\pm 0.4 \%$. 
The concentrations of $\mathrm{O}_{2}, \mathrm{CO}_{2}, \mathrm{CO}, \mathrm{NO}_{\mathrm{x}}$ in flue gases were measured by a flue gas analyser ABB AO 2020 with sensor modules Uras 26 (NDIR photometer for continuous $\mathrm{CO}_{2}, \mathrm{CO}, \mathrm{NO}_{\mathrm{x}}$ measuring) with accuracy $\leq 1 \%$ of span and oxygen analyser module Magnos 206 (paramagnetic behaviour of oxygen) with accuracy $\pm 0.5 \%$. The suction pyrometer is used for sampling exhaust gas. Pyrometer output socket connects to the flue gas analyser. The piping for the sampling operations must be incorporated with means for cooling, cleaning and drying flue gas samples. ABB analyser AO 2020 is constructed according to the requirements and nature of the measurement. Recorded the emission values in ppm units (parts per million). These values were converted to $\mathrm{mg} \cdot \mathrm{m}^{-3}$. The normalized concentration of oxygen in the flue gas from a boiler $\mathrm{O}_{2 n}$ is $10 \%$. Therefore, the measured values of each emission are recalculated.

Particulate matter measurement was conducted by gravimetric method by using of the isokinetic automatic sampler TECORA Isostack Basic. Gravimetric method is given by the standard ISO $9096[9,10]$. It is a manual, single-use method where samples are taken by a probe from flowing gas. This method gives an average value of PM for a given span of time within which a partial flow from an exhaust gas sample is taken. Exhaust gases are guided through filtration or sediment systems which catch either all particles or only those of pre-defined size. Filtration materials are weighed before and after measurements and final mass concentration is calculated from a sample volume. Sampling probes can be placed either directly into hot flow of exhaust gases or outside the flow (these systems must be heated to avoid condensation or nucleation). Solid particles are collected from flowing gas with the help of the probe. From them an average concentration of flowing gas particles is determined. Exhaust gases were taken from a chimney duct with the help of a three-stage separation impactor. The sampling was conducted at the same speed of exhaust gas flow as in the pipe. Hot gas was led from the pipe through cooling and drying equipment up to the sampling unit. In the cooling equipment exhaust gases were cooled and water vapour was removed from the exhaust gas sample. In the silica gel-water absorption tower residual moisture of exhaust gases was removed. The accuracy of this method influences various parameters, mainly differential pressure in Pitot tube $\pm 4 \mathrm{~Pa}$, temperature of flue gas $\pm 0.7 \%$, flow rate and volume measure $\pm 2 \%$ and filter weight $\pm 0.1 \mathrm{mg}$. The sampling was isokinetic and the isokinetic deviation during all experiments was in the range $-5.7 \div 4.9 \%$.

\section{Results}

The measurement values compare the combustion of four identical sample types in two different types of combustion burners. Table 1 shows the average measured values of the determined parameters during the experiments on retort burner.
Table 1 Average measured values of the determined parameters during the experiments on retort burner

\begin{tabular}{|c|c|c|c|c|}
\hline \multirow{2}{*}{ 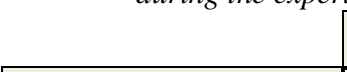 } & \multirow{2}{*}{ V1 } & \\
\hline & & $\mathbf{V 2}$ & V3 & V4 \\
\hline Thermal power $(\mathrm{kW})$ & 13.2 & 15 & 14.6 & 14.4 \\
\hline Efficiency $(\%)$ & 75.3 & 76.4 & 75.7 & 75.7 \\
\hline $\mathrm{O}_{2}(\%)$ & 14.1 & 13.1 & 13.1 & 13 \\
\hline $\mathrm{CO}_{2}(\%)$ & 6.8 & 7.6 & 7.6 & 7.7 \\
\hline $\mathrm{CO}_{10 \%}\left(\mathrm{mg} \mathrm{m}^{-3}\right)$ & 1381.8 & 929.2 & 771.9 & 703.4 \\
\hline NOx10\% $\left(\mathbf{m g} \cdot \mathrm{m}^{-3}\right)$ & 232.6 & 254.5 & 243.9 & 271.6 \\
\hline $\mathrm{OGC}_{10 \%}\left(\mathrm{mg} \cdot \mathrm{m}^{-3}\right)$ & 20.1 & 21.4 & 32.6 & 29.8 \\
\hline $\mathrm{PM}_{10 \%}\left(\mathrm{mg} \cdot \mathrm{m}^{-3}\right)$ & 25.4 & 29.5 & 35.3 & 41.1 \\
\hline
\end{tabular}

Table 2 shows the average measured values of the determined parameters during the experiments on rotary tube burner.

Table 2 Average measured values of the determined parameters

\begin{tabular}{|c|c|c|c|c|}
\hline & V1 & $\mathbf{V 2}$ & V3 & V4 \\
\hline Thermal power $(\mathrm{kW})$ & 14.6 & 17.8 & 17.9 & 18.2 \\
\hline Efficiency $(\%)$ & 87.6 & 90.4 & 90.9 & 90.6 \\
\hline $\mathrm{O}_{2}(\%)$ & 12.2 & 6.4 & 5.4 & 7.5 \\
\hline $\mathrm{CO}_{2}(\%)$ & 8 & 14.3 & 15.4 & 13.4 \\
\hline $\mathrm{CO}_{10 \%}\left(\mathrm{mg} \mathrm{m}^{-3}\right)$ & 795.8 & 1598.1 & 2718.5 & 3613.7 \\
\hline NOx10\% $\left(\mathrm{mg}^{-\mathrm{m}^{-3}}\right)$ & 228.6 & 177.1 & 149.1 & 199.9 \\
\hline $\mathrm{OGC}_{10 \%}\left(\mathrm{mg} \cdot \mathrm{m}^{-3}\right)$ & 30.3 & 13.3 & 84.4 & 69.7 \\
\hline $\mathrm{PM}_{10 \%}\left(\mathbf{m g} \cdot \mathbf{m}^{-3}\right)$ & 35.6 & 46.4 & 48.5 & 57.7 \\
\hline
\end{tabular}

It is clear from the measured values that when using a rotary burner, the efficiency of the conventional type of retort burner was increased by almost $15 \%$. Increasing combustion efficiency has led to a reduction in the chimney temperature and temperature in the combustion chamber, which has been positively reflected in a decrease in $\mathrm{NO}_{\mathrm{X}}$ emissions. Also, the bark used has had a positive effect on the fire turbulence, which has led to an increase in plant performance.

Figure 4 shows time course of thermal power of heat source with various burners. Retort burner had more stable operation which cause almost constant thermal power. On the other hand, the operation of tube burner was not so stable, but the combustion efficiency was higher.

A major disadvantage of tube burning using was the excessively high emission production of $\mathrm{CO}$ caused by the dropping of the unburned parts of the pellets from the burner compartment which is into the ashtray what is shown on figure 5. Despite this the average $\mathrm{CO}$ production during tube rotary burner using is half in comparison with boiler operation with retort burner. 


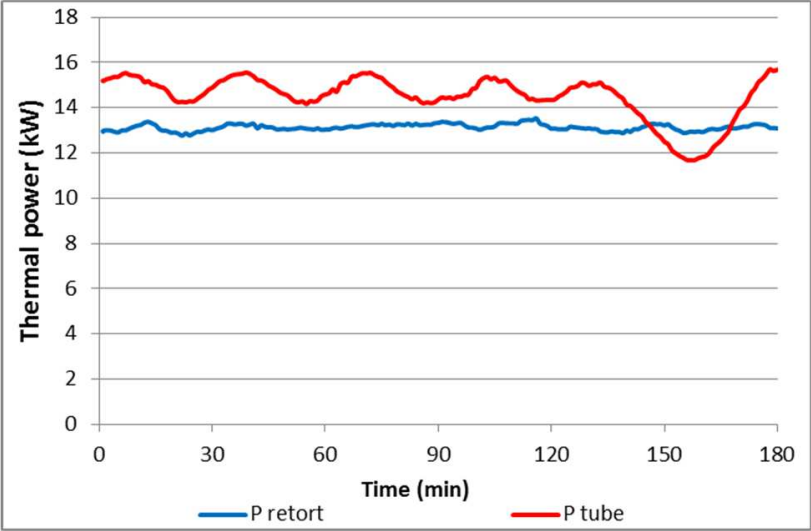

Figure 4 Time course of thermal power of heat source with various burners

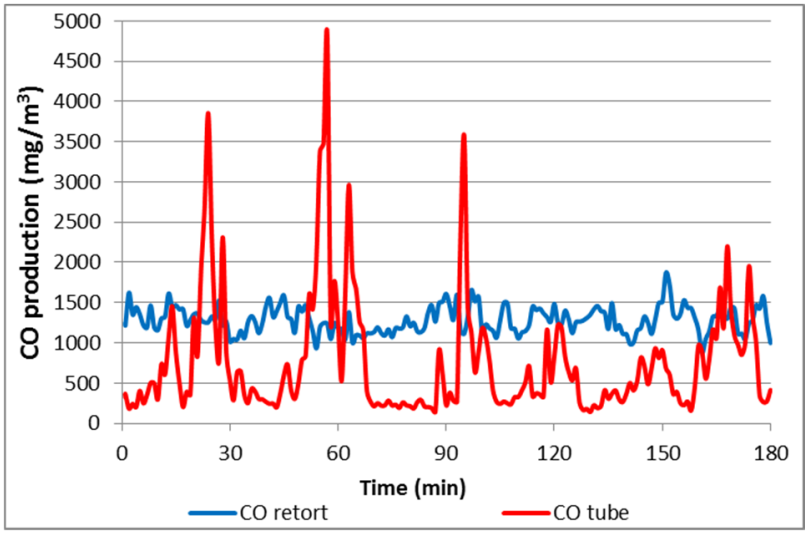

Figure 5 Time course of CO production of heat source with various burners

\section{Conclusion}

Research has shown that the burning direction and slope of the burner significantly affect the efficiency and smooth operation of the combustion plant. More modern horizontal burner types do not have to overcome the gravitational force that acts on the ash and the resulting sintering prevents these particles from blowing out of the burner combustion chamber and causes the combustion chamber to clog. On the other hand, the reduced effect of the gravitational force on the non-burnt fuel causes the still unburdened pellets to be blown into the burner into the combustion chamber where these pellets do not fully heat up or imperfectly without optimum air and temperature access. This leads to an increase in mechanical and chemical loss, and in particular an increase in $\mathrm{CO}$ emissions. A suitable compromise is the use of a rotary burner with a suitable tilt angle, which would increase the gravitational force required to blow the unburnt particles from the burner.

\section{Acknowledgement}

This article was supported by the projects KEGA 033ŽU4/2018 "Heat sources and pollution of the environment", APVV-15-0790 "Optimalization of biomass combustion with low ash melting temperature" and VEGA 1/0233/19
"Construction modification of the burner for combustion of solid fuels in small heat sources".

\section{References}

[1] JANDAČKA，J., MIČIETA，J.，HOLUBČÍK， M., NOSEK, R.: Innovation to make the biomass combustion process more efficient, Žilina, EDIS, pp. 265, 2016. (Original in Slovak)

[2] MIKULOVA, Z., VITAZEK, I.: Proportion of volatile matter in selected biofuels, Proceedings of International PHD Students Conference, (Mendelnet 2016), pp. 892-897, 2016.

[3] BRESTOVIČ, T., JASMINSKA, N.: Software support development for numerical solution of ansys CFX, Acta Mechanica et Automatica, Vol. 7, No. 4, pp. 215-221, 2013.

[4] DZURENDA, L., HRONCOVÁ, E., LADOMERSKÝ, J.: Extensive Operating Expe-riments on the Conversion of Fuel-Bound Nitrogen into Nitrogen Oxides in the Combustion of Wood Fuel, Forests, Vol. 8, No. 1, pp. 1-9, 2017.

[5] WEBER, R., SZLEK, A., NOSEK, R.: Time-dependent combustion of solid fuels in a fixed-bed: measurements and mathematical modeling, Energy \& fuels, Vol. 28, No. 8, pp. 4767-4774, 2013.

[6] CHUDÍKOVÁ, P., TAUŠOVA, M., ERDELYIOVA, K,. TAUŠ, P.: Potential of dendromass in Slovak Republic and its actual exploitationin thermic economy, Acta Montanistica Slovaca, Vol. 15, No. 2, pp. 139-145, 2010.

[7] DZURENDA, L., BANSKI, A.: Dependence of the boiler flue gas losses on humidity of woody biomass, Archives of Thermodynamics, Vol. 36, No. 4, pp. 7786, 2015.

[8] RIMÁR, M., FEDÁK, M., KORSHUNOV, A., KULIKOV, A., MIŽÁKOVÁ, J.: Determination of Excess Air Ratio During combustion of Wood Chips Respect to Moisture Content, Acta Facultatis Xylologiae, Vol. 58, No. 2, pp. 133-140, 2016.

[9] HORAK, J., KUBONOVA, L., KRPEC, K., HOPAN, F., KUBESA, P., MOTYKA, O., LACIOK, V., DEJ, M., OCHODEK, T., PLACHA, D.: PAH Emissions from Old and New Types of Domestic Hot Water Boilers, Environmental Pollution, Vol. 225, pp. 31-39, 2017.

[10] HONUS， S., POSPÍŠILÍK， V., JURSOVÁ, S., ŠMÍDA, Z., MOLNÁR, V., DOVICA, M.: Verifying the Prediction Result Reliability Using k- $\varepsilon$, Eddy Dissipation, and Discrete Transfer Models Applied on Methane Combustion Using a Prototype LowPressure Burner, Advances in science and technology-research journal, Vol. 11, No. 4, pp. 252259, 2017.

[11] ESKILSSON, D., RÖNNBÄCK, M., SAMUELSSON, J., TULLIN, C..: Optimisation of efficiency and emissions in pellet burners, Biomass and Bioenergy, Vol. 27, No. 6, pp. 541-546, 2004. 
[12] DIAS, J., COSTA, M., AZEVEDO, J.L.T.: Test of a small domestic boiler using different pellets, Biomass and Bioenergy, Vol. 27, No. 6, pp. 531-539, 2004.

\section{Review process}

Single-blind peer review process. 